\title{
Characterization of laser-processed thin ceramic membranes for electrolyte-supported solid oxide fuel cells
}

\author{
J.A. Cebollero, R. Lahoz, M.A. Laguna-Bercero, J.I. Peña, A. Larrea*, \\ V.M. Orera \\ Instituto de Ciencia de Materiales de Aragón, U. Zaragoza-CSIC, C/ María de Luna 3, E-50.018 Zaragoza, Spain
}

\section{A R T I C L E I N F O}

Article history:

Received 14 October 2016

Received in revised form

20 December 2016

Accepted 22 December 2016

Available online $\mathrm{xxx}$

Keywords:

SOFC

Solid electrolytes

Laser machining

Self-supporting ceramic membranes

\begin{abstract}
A B S T R A C T
By laser machining we have prepared thin and self-supported yttria stabilized zirconia (YSZ) electrolytes that can be used in electrolyte-supported solid oxide fuel cells for reducing the operation temperature. The membranes, which are supported by thicker areas of the same material, have an active area of $\sim 20 \mu \mathrm{m}$ in thickness and up to $8 \mathrm{~mm}$ in diameter. Buckling limits the maximum size of the thin areas to below $1 \mathrm{~mm}$, the overall effective active area being formed by multiple thin areas bounded by ribs. Electron Backscattering Diffraction experiments determined that there are not significant strains inside the membranes and that the heat-affected zone is confined to a shallow layer of $\sim 1-2 \mu \mathrm{m}$. The bending strength of the membranes decreases by $\sim 26 \%$ as a result of the surface microcracking produced by the laser machining. The membranes have a roughness of $\sim 2.5 \mu \mathrm{m}$ and are coated by a layer of nanoparticles produced by the laser ablation. This coating and small roughness is not detrimental for the cathodic polarization of the cells. Conversely, the cathode polarization resistance decreases $\sim 5 \%$ in the $650-850{ }^{\circ} \mathrm{C}$ temperature range.
\end{abstract}

๑ 2017 Hydrogen Energy Publications LLC. Published by Elsevier Ltd. All rights reserved.

\section{Introduction}

Solid oxide fuel cells (SOFC) can transform hydrogen into work with high efficiency and no emission of contaminants or sound [1]. Moreover, the heat generated inside the cell can be used for fuel reforming, allowing SOFC devices to also use hydrocarbons as fuel. Thus, they can take advantage of the current natural gas distribution network. In addition they are very suitable for portable applications, because they can use commercially available liquid fuels. The commercialization of small portable units for mobile electronic devices based on microtubular SOFC technology [2] is about to begin [3].

The electrolyte of the SOFC is an ionic conducting membrane, the standard material being the yttria-stabilized zirconium oxide (YSZ). YSZ is a pure oxygen ion conductor that presents good conductivity values at temperatures above $800{ }^{\circ} \mathrm{C}$ [4], as well as good mechanical and thermal stability. However, material demand for SOFC components is quite stringent due to the high operation temperature. Thus, lowering the operation temperature improves the long-term stability of the cell and permits the reduction in price of the

\footnotetext{
* Corresponding author.

E-mail address: alarrea@unizar.es (A. Larrea).
} 
stack by allowing the use of cheaper materials for the rest of the cell components. Accordingly, thin electrolytes are deposited by different techniques (conventional ceramic techniques such as dip-coating or spray-painting [2], as well as Physical Vapor Deposition techniques, for example sputtering or Pulsed Laser Deposition [5]) over one of the electrodes, which act as structural support for the cell [6]. Typical electrolyte thickness is about $10-30 \mu \mathrm{m}$, while the anode is usually a porous Ni-YSZ composite about $300 \mu \mathrm{m}$ thick, thicker than the $30 \mu \mathrm{m}$ of a standard functional electrode. Nevertheless, the anode-supported configuration, the most prevalent configuration for Intermediate Temperature SOFC (IT-SOFC), also has some drawbacks. In addition to gas transport restriction due to the thickness of the electrode, anode-supported SOFCs can present redox stability problems [7]. Re-oxidation of the metal particles in the anode, produced for instance by failures in the fuel supply, can create mechanical damages that will degrade the cell performance and, eventually, compromise its integrity.

To reduce the problems of redox cycling, the electrolytesupported configuration can be chosen because it presents better mechanical resistance. In this configuration, thin porous electrodes $(30-50 \mu \mathrm{m})$ are deposited over a sintered electrolyte membrane, which acts as mechanical support for the cell. Thus, gas transport in the electrodes is not a problem. Moreover, the electrolyte is usually the ceramic layer with the highest sintering temperature, as it is the only dense and gastight layer. Hence, the electrodes can be deposited later and sintered at lower temperatures, favouring the achievement of the optimum porosity and reducing the reactivity between the different chemical compounds. The main disadvantage of this configuration is that it requires high operation temperature (usually $900-1000{ }^{\circ} \mathrm{C}$ for YSZ electrolytes) to reduce the ohmic resistance.

Special mention should also be made to the micro-solid oxide fuel cell ( $\mu$-SOFC) configuration. These devices use ultrathin ( 100 nm or less) freestanding membranes prepared by microfabrication methods. The goal is to prepare small-scale SOFC devices working at very low temperatures $\left(\sim 500{ }^{\circ} \mathrm{C}\right)$ and able to supply energy in the range of mW's. Various substrates have been tested to support the membranes, the silicon platform being probably the most successful because it takes advantage of the huge development in the microfabrication silicon technology. A review containing information about the various kinds of substrates used to support the membranes and the geometries of the cells can be found in Refs. [8,9]. Several groups have made significant progress in recent years. For instance a power density higher than $1 \mathrm{~W} /$ $\mathrm{cm}^{2}$ at $500{ }^{\circ} \mathrm{C}$ has been reported in cells consisting of nanoporous Pt electrodes and $100 \mathrm{~nm}$ thin YSZ freestanding electrolytes [10]. However, scalability is still one of the greater challenges for $\mu$-SOFC devices. Most of the $\mu$-SOFC devices consist of very small thin electrochemically-active cells supported by non-active Si pyramids, the active area representing only about $3 \%$ of the total area. Advances in scalability have been obtained by using metallic grids as mechanical supports [11]. Another major concern of these devices is their poor stability due to two main reasons: the difference in coefficient of thermal expansion between the substrate and the electrolyte, which produces a mechanical degradation of the cell with thermal cycles [12] and the inherent microstructural instability of the nano-porous Pt electrodes [10].

In this paper we explore a distinctive alternative trying to get the best characteristics of the different configurations we have mentioned. We used the laser machining technique to prepare thin self-supporting ionic conducting membranes that were reinforced by thicker areas of the same materials, obtaining in this way complete thermo-mechanical integration [13]. Laser machining is now a widespread technique for the production of high-quality ceramics at competitive prices [14]. The membranes can be used for preparing electrolytesupported SOFC working at IT. Moreover, the same technology can also be applied to other membranes such as catalytic coatings, sensors and $\mathrm{H}_{2}$-permeable membranes based on mixed proton-electron conductors (MEPC). These materials provide a net flux of $\mathrm{H}_{2}$ uniquely driven by the chemical potential gradient across the membrane at moderate temperatures. Ceramic-based MPEC membranes display better thermal and mechanical stability, long-term durability and cost effectiveness than polymeric membranes or membranes based on precious metal alloys $[15,16]$.

In the paper we first analyse the different contribution to residual stress in an electrolyte-supported SOFC and estimate the maximum size of the thin membranes with no buckling. Then we describe the optimization of the laser-machining procedure and the microstructural and electrochemical characterization of the membranes. We used confocal optical profilometry and Scanning Electron Microscopy (SEM) for determining the thickness and surface finishing of the membranes. Electron Back-Scattering Diffraction technique (EBSD) was used to investigate the in-depth profile of the residual strains produced by the laser machining. The mechanical properties of the samples were tested by three point bending tests. Transmission Electron Microscopy (TEM), electron diffraction and Energy Dispersive Spectroscopy (EDS) were used to characterise the particles ejected during the ablation process, identifying the different mechanisms of resolidification and redeposition on the surface. The electrical performance of the membranes was finally tested by Electrochemical Impedance Spectroscopy (EIS).

\section{Materials and methods}

We processed commercial 8YSZ $\left(\mathrm{ZrO}_{2}\right.$ doped with $8 \mathrm{~mol} \%$ $\mathrm{Y}_{2} \mathrm{O}_{3}$ ) plates from Kerafol $\mathrm{GmbH}$. The original plates were $50 \times 50 \mathrm{~mm}^{2}$ in size and $150 \pm 15 \mu \mathrm{m}$ thick. The laser used was a Q-switched diode-pumped laser (Rofin PowerLine S3 SHG) emitting at $532 \mathrm{~nm}$ wavelength (nominal power $2 \mathrm{~W}, \mathrm{TEM}_{00}$ beam type, quality factor $\mathrm{M}^{2}<1.2$, repetition rate range $15-400 \mathrm{kHz}$ ). The laser was equipped with two galvanometric mirrors to control the beam position over the sample and scan its surface. These galvanometric mirrors are, in turn, computer-controlled through Computer Assisted Design (CAD) software. This is a low-cost commercial laser currently used in the photovoltaic industry. The focal distance of the laser lens was $100 \mathrm{~mm}$ and thus the machinable area $60 \times 60 \mathrm{~mm}^{2}$. Optical-grade mechanical components were used to position the laser optics and the sample. 
The size and in-depth profile of the machined areas were determined with an optical confocal microscope (Nikon Sensofar PL 42300$)$. The microstructure was studied using a field emission scanning electron microscope (FESEM model Merlin from Carl Zeiss) and a transmission electron microscope (TEM model 2000FXII from Jeol), both equipped with Energy Dispersive Spectroscopy (INCA-350 system form Oxford Instruments). TEM-EDS quantitative analysis was done using the Cliff-Lorimer method and thin film approximation [17]. The Y-Zr sensitivity factor was experimentally determined using 8YSZ powder (Tosoh) as standard. The SEM specimens were Pt coated to avoid charging.

The EBSD experiments were carried out using an HKL detection system (Oxford Instruments) installed in the Merlin FESEM. The EBSD specimens were embedded in epoxy resin and polished in cross-sections according to a polishing procedure previously published [18]. The electron probe had $20 \mathrm{kV}$ energy and $1.6 \mathrm{nA}$ of current. Charge was compensated in-situ using a gas injection system [19]. Moreover, the observed YSZresin interface was placed in the bottom part of the tilted specimen $\left(70^{\circ}\right)$, because we realized that this apparently insignificant experimental detail was critical to avoid charging. The EBSD patterns were re-analyzed off-line using level 4 for the AFI parameter, Hough resolution 100, 10 detected bands and 100 reflectors in the crystallographic phase [20].

Mechanical characterization was performed by three point bending tests using an Instron 5565 testing machine equipped with a $100 \mathrm{~N}$ maximum load cell. The bending test jig had $10 \mathrm{~mm}$ of support span.

Electrochemical tests were performed using symmetrical cells composed of a machined (or non-machined for comparison) membrane and a standard bilayered LSM/YSZ SOFC cathode (LSM/YSZ 50/50 vol\% as functional layer and 80/20 vol $\%$ as current collector layer) deposited on both surfaces by dip coating according to the procedure described in Ref. [21]. Pt paste was added to improve current collection. Samples were mounted on a button-cell test rig (NorECs Probostat) and the electrochemical measurements were performed using a Zahner Zennium workstation. We used sinusoidal signal amplitude of $20 \mathrm{mV}$ over the frequency range of $100 \mathrm{kHz}$ down to $0.1 \mathrm{~Hz}$, at temperatures between $650^{\circ} \mathrm{C}$ and $850^{\circ} \mathrm{C}$.

\section{Mechanical estimations for the membrane design}

The mechanical properties of the self-supporting membranes have to be able to address the requirements for making an electrolyte-supported SOFC. We need to deposit $~ 30 \mu \mathrm{m}$ thick electrodes over a $\sim 20 \mu \mathrm{m}$ thick sintered electrolyte. The electrolyte is thus subject to mechanical stress due to electrode densification during sintering and to the differences in the Coefficients of Thermal Expansion (CTE) with the electrodes. Although mechanical behaviour of the laminated structures found in SOFC cannot always be predicted from the properties of individual components, in this section we are going to analyze the different contributions to the stress. Our aim is to obtain the approximate value of these stresses or, at least, some boundaries to get the appropriate consequences for the cell design.

\section{Stresses produced by constrained sintering}

When the electrode densifies by sintering on the rigid electrolytic membrane, the membrane is placed in biaxial compressive tension and the electrode densification occurs only in the vertical direction. Modelization of constrained sintering is not an easy task, but it is usually described using a linear viscous deformation model. Although the sintering compact can be considered as viscoelastic, the elastic component is rather small, given that the densification strains are enormous compared to the elastic strains [22]. In this framework, the sintering-induced stress for a constrained film is:

$\sigma_{s}=\frac{E_{p} \cdot \dot{\varepsilon}_{f}}{1-\nu_{p}}$

where $E_{p}$ is the uniaxial viscosity, $\dot{\varepsilon}_{f}$ the unconstrained sintering rate and $\nu_{p}$ the viscous Poisson ratio. However, there is no reliable data for estimating $\sigma_{s}$ during electrode formation in SOFC. Atkinson et al. [23] measured the in-plane stress induced during constrained sintering by a $10-13 \mu \mathrm{m}$ thick 3YSZ film deposited over a $300 \mu \mathrm{m}$ thick sintered substrate of the same material. They found that $\sigma_{s}$ had a maximum value of approximately $3 \mathrm{MPa}$ at the mid range of the sintering temperature. They explained this dependence on temperature by discussing the relative activation energies for the different available diffusion pathways, as $E_{p}$ and $\dot{\varepsilon}_{f}$ are both controlled by the slowest diffusion cation but in opposite senses. They also indicated that this behaviour is consistent with previous literature results for constrained sintering of bulk alumina (maximum stress about 3.6 $\mathrm{MPa}$ at $1200{ }^{\circ} \mathrm{C}$ [24]) and with the estimations that can be obtained from the thermodynamic sintering potential, which is a function of the surface energy and the pore structure (about $8 \mathrm{MPa}$ assuming that the YSZ surface energy is $\sim 2 \mathrm{~J} / \mathrm{m}^{2}$ and the radius of the pores $\sim 0.5 \mu \mathrm{m}$ ). Accordingly, we can reasonably presume that compressive stresses produced by sintering of YSZ-based electrodes (YSZ$\mathrm{NiO}$ and YSZ-LSM) are below $10 \mathrm{MPa}$.

\section{Stresses produced by elastic thermal mismatch}

The main source of stress in a SOFC is the difference in CTE of the cell components when cooling form the sintering temperature and during service cycling. If we consider a bilayer fabricated at an elevated temperature, $\mathrm{T}_{0}$, and cooled down to $\mathrm{T}$, the two component materials suffer a CTE mismatch stress that can be expressed as a function of the mismatch strain $\varepsilon_{M}$ [25]:

$\varepsilon_{\mathrm{M}}=\int_{\mathrm{T}}^{\mathrm{T}_{0}}\left(\alpha_{2}-\alpha_{1}\right) \mathrm{dT}$

as:

$$
\begin{aligned}
& \sigma_{R_{1}}=-\frac{\varepsilon_{M} \cdot E_{1}^{\prime}}{1+\frac{t_{1} \cdot E_{1}^{\prime}}{t_{2} \cdot E_{2}^{\prime}}} \\
& \sigma_{R_{2}}=-\sigma_{R_{1}} \frac{t_{1}}{t_{2}}
\end{aligned}
$$


Here $\sigma_{R_{12}}$ are the stresses over the electrolyte and the electrode respectively, $\alpha_{1,2}$ the CTEs of the bilayer components $\left(\alpha_{1}<\alpha_{2}\right), t_{1,2}$ their thicknesses and $E^{\prime}=E /(1-v)$, where $E$ and $v$ are the Young's modulus and Poisson's ratio respectively.

According to equation (3) we have calculated the thermal stress produced by cooling after sintering the NiO-YSZ cell anode $\left(t_{2}=30 \mu \mathrm{m}\right)$ on a $t_{1}=20 \mu \mathrm{m}$ thick YSZ membrane. Creep should not be significant for residual stress relief in YSZ at temperatures below $1100^{\circ} \mathrm{C}$, according to Atkinson and Selcuk experiments [26]. Thus, we selected a stress free temperature of $\mathrm{T}_{0}=1200{ }^{\circ} \mathrm{C}$ and used the elastic parameters collected in Table 1 [27-31]. With this data we obtained a compressive residual stress in the electrolyte of $\sigma_{\mathrm{R}_{1}}=-298 \mathrm{MPa}$. For LSMYSZ composite cathodes we have not found the necessary data in the literature, but for 33\% porosity LSM cathode sintered at $1050{ }^{\circ} \mathrm{C}$ over a $\mathrm{t}_{1}=20 \mu \mathrm{m}$ YSZ membrane we get $\sigma_{\mathrm{R}_{1}}=-53 \mathrm{MPa}$. Finally, for the normal service cycling of the cell after reducing the $\mathrm{NiO}$ to form the anode, considering a NiYSZ/YSZ bilayer at an operating temperature of $800{ }^{\circ} \mathrm{C}$ we obtain $\sigma_{\mathrm{R}_{1}}=-144 \mathrm{MPa}$. Thus, the highest stresses are produced after sintering the anode and could be up to about $300 \mathrm{MPa}$. We have to note that in these calculations we have not taken into account the possible stress relief by extensive channel cracking, that could significantly reduce the real stress from the expected thermoelastic stress [31].

\section{Buckling of thin plates}

Buckling is a situation of elastic instability that arises when a slender piece is subjected to compressive stress higher than certain critical load [32]. In this situation, important nonlinear strains perpendicular to direction of the compressive stresses are developed. Thus, buckling of ceramic pieces can easily cause the breakdown of the component because tensile strength of ceramics is much lower than compressive strength due to the stress intensity enhancement produced by the presence of flaws. Typical values for the strength of YSZ under compression are about $1 \mathrm{GPa}$ [33], while the tensile strength for the same material is $200 \mathrm{MPa}$ [34]. The critical buckling compressive load of a circular plate with clamped edges can be expressed according to [35]:

$\sigma_{\mathrm{BC}}=1.22 \frac{E}{1-\nu^{2}}\left(\frac{\mathrm{t}}{a}\right)^{2}$

Table 1 - Elastic parameters of the components of a SOFC according to references [27-31].

\begin{tabular}{cccc} 
& $\begin{array}{c}\text { Young's } \\
\text { modulus } \\
(\mathrm{GPa})\end{array}$ & $\begin{array}{c}\text { Poisson's } \\
\text { coefficient }\end{array}$ & $\begin{array}{c}\text { Coefficient of } \\
\text { thermal } \\
\text { expansion } \\
\left(\times 10^{-6} \mathrm{~K}^{-1}\right)\end{array}$ \\
\hline Electrolyte (YSZ) & 220 & 0.320 & 10.8 \\
Anode (NiO-YSZ) & 161 & 0.317 & 12.3 \\
$\begin{array}{c}\text { Anode (Ni-YSZ 36\% } \\
\text { porosity) }\end{array}$ & 69 & 0.317 & 12.6 \\
$\begin{array}{c}\text { Cathode (LSM 33\% } \\
\text { porosity) }\end{array}$ & 35 & 0.250 & 11.7 \\
\hline
\end{tabular}

where $E$ is the Young's modulus, $\nu$ the Poisson's coefficient, $t$ the plate thickness and $a$ the plate radius. According to this expression the radius of the plates is limited because they must have a critical buckling compressive load higher than maximum compressive stresses produced during SOFC preparation.

\section{Experimental results and discussion}

\section{Laser machining}

For machining the samples we used a pulsed laser, in the nanosecond regime, focused on the surface of the ceramic membrane. Although YSZ is mainly transparent in the visible region [13], it has been shown that is possible to machine YSZ by a photo-thermal laser ablation using solid-state lasers with emission in the green $(532 \mathrm{~nm}$ ) or in the infrared (1064 nm) regions [36]. The repetition rate was set to $15 \mathrm{kHz}$ to obtain the minimum pulse width of the laser source, $5 \mathrm{~ns}$, in order to minimize thermal effects. For this repetition rate the pulse energy was $67 \mu \mathrm{J}$. Then, the optimum scan speed for maximum material removal was obtained at $150 \mathrm{~mm} \mathrm{~s}^{-1}$. The separation distance between the scanning lines was set to $10 \mu \mathrm{m}$ to get the same pulse separation in the directions perpendicular and parallel to the scanning direction. The sample was placed $0.4 \mathrm{~mm}$ under the focus position to maximize the removal rate $\left(\sim 0.01 \mathrm{~mm}^{3} / \mathrm{s}\right)$. In this situation the area irradiated in every pulse is about 3 times larger than in focus position, but still receives enough irradiance to evaporate the material [37].

In these conditions, as the beam spot was controlled by the galvanometric mirrors, it was possible to reduce the thickness of selected parts of the ceramic, shaping it with a lateral resolution of $\sim 10 \mu \mathrm{m}$ and in-depth resolution of $3 \mu \mathrm{m}$. For many of the tests we machined button-type samples $(21 \mathrm{~mm}$ outer diameter) thinning the central part of the ceramic piece $(\varnothing 8$ $\mathrm{mm}$ ) on only one side. The thickness of the thin area was $\sim 20 \mu \mathrm{m}$ and the parallelism between the upper (laser-processed) and lower (non-processed) surfaces was about 1/4000. The unprocessed outer ring (150 $\mu \mathrm{m}$ thick) works both as mechanical support of the thin area and as contact and sealing area (see Fig. 1). However, although it is possible to fabricate $20 \mu \mathrm{m}$ thick plates of $8 \mathrm{~mm}$ in diameter using laser machining (Fig. 1a), or even more slender ones, these pieces have a buckling critical load of only $7 \mathrm{MPa}$ and will break under the compressive stresses that occur after sintering. Thus, if we intend to use conventional SOFC electrodes that will create compressive stresses up to $300 \mathrm{MPa}$, the radius of the thin areas has to be lower than $0.6 \mathrm{~mm}$. In fact, if we impose as security limit $\sigma_{\mathrm{Bc}}=500 \mathrm{MPa}$, we obtain the critical radius $a=0.48 \mathrm{~mm}$. Merging different thin zones bounded by ribs, as shown in Fig. 1b, can finally enlarge the overall active area of the membrane. For instance, in the layout shown in Fig. 1b, consisting of $20 \mu \mathrm{m}$ thin circular areas of $1 \mathrm{~mm}$ in diameter separated by thicker ribs $100 \mu \mathrm{m}$ apart, $75 \%$ of the total area does correspond to the minimum thickness $(20 \mu \mathrm{m})$, while the remaining $25 \%$ have an intermediate thickness of $70 \mu \mathrm{m}$. Different layouts can be simply obtained by means of the CAD software that controls the laser galvanometric mirrors. 

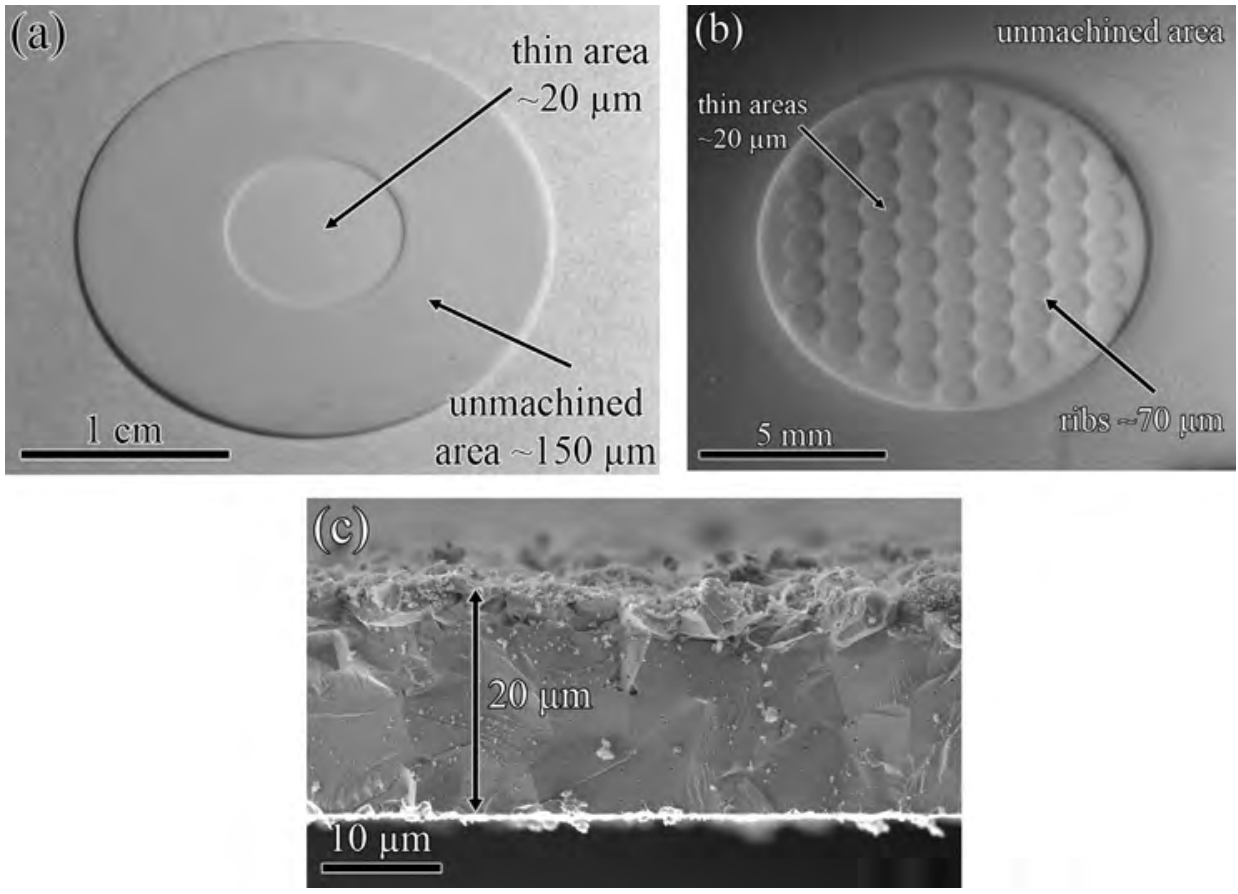

Fig. 1 - Images of two machined samples. a) With a central thin area of $8 \mathrm{~mm}$ in diameter. b) Consisting of multiple thin areas of $1 \mathrm{~mm}$ in diameter separated by $70 \mu \mathrm{m}$ thick ribs. c) SEM image of the fractured cross-section of a membrane.

\section{EBSD mapping of the residual strains in the membrane}

Part of the energy deposited over the sample by the laser pulses is thermally transferred to the ceramic. This transfer of energy is negligible for lasers with pulse width in the femtosecond region, but not for lasers in the nanosecond region. Thus, as YSZ is a poor thermal conductor, the sample surface gets heat very locally. Large temperature gradients give rise to inhomogeneous thermal expansion and may produce plastic deformation and crack formation that could even lead to the breakdown of the ceramic sample. Although the laser processing parameters are adjusted to prevent sample breakdown, to get some information about the size of the heataffected zone (HAZ) it is necessary to foresee the mechanical performances of the membranes. Thus we have used EBSD to map the presence of strains in materials [38] and consequently estimate the depth of the heat-affected zone (HAZ). Using EBSD we can automatically obtain an electron diffraction pattern at every point of a surface. Analyzing these patterns we can obtain, among other information, the crystallographic orientation at every point of the sample.

Hence EBSD maps covering areas $200 \mu \mathrm{m}$ below the machined surface were obtained. Fig. $2 a$ and $b$ are EBSD orientation maps of the cross-sections of superficial area of a laser-machined surface and of an unprocessed surface. The grains can be identified because they show a uniform colour (different crystallographic orientations are represented by different colours) and, in addition, black lines mark grain boundaries. There is no apparent difference between the processed and unprocessed surfaces, except that the superficial grains of the processed surface are more elongated. The aspect ratio of the superficial grains is 0.26 (standard deviation 0.14 ), while the aspect ratio of the inner grains cut by a random surface, for comparison with the superficial grains, is 0.62 (standard deviation 0.35 ). This difference is probably because the surface grains are formed by resolidification of melted liquid. But this shallow affectation is confined to a layer of less than about 1-2 $\mu \mathrm{m}$ deep. Moreover, in Fig. $2 \mathrm{c}$ and $d$ we represent the Local Misorientation Maps of the same areas, as in Fig. $2 a$ and $b$ respectively. In these maps we have represented the average crystallographic misorientation between every pixel and its surrounding pixels, assigning the mean value to that pixel, which is plotted according to a rainbow colour scale to highlight the zones of higher deformation. The maps of the processed and unprocessed areas are very similar and we cannot appreciate the presence of deformed regions associated to the laser machining, the deformation being, in general, lower than $0.15^{\circ}$. These results are in good agreement with simple estimations of the size of the HAZ [39], which is related to melting in the case of nanosecond pulses. The width of the HAZ can be roughly approximated to the heat penetration depth $l_{T} \sim 2\left(D \tau_{1}\right)^{1 / 2}$, where $D$ is the thermal diffusivity and $\tau_{1}$ the pulse width. Typical values for $l_{T}$ in YSZ with $\tau_{1} \sim 5$ ns are about $0.1 \mu \mathrm{m}$.

\section{Bending tests}

On a relatively thin substrate, unequal compressive stresses on both sides of the membrane may cause the substrate to bend. Bending is allowed to occur to balance the bending moment induced by the asymmetric stresses [40]. The bending moment depends on the residual compressive stresses caused by anode and cathode, thicknesses of the electrodes and the elasticity and thickness of the membrane. Accurate calculation of this parameter is not an easy task and it is beyond the scope of this paper. On the other hand, the 

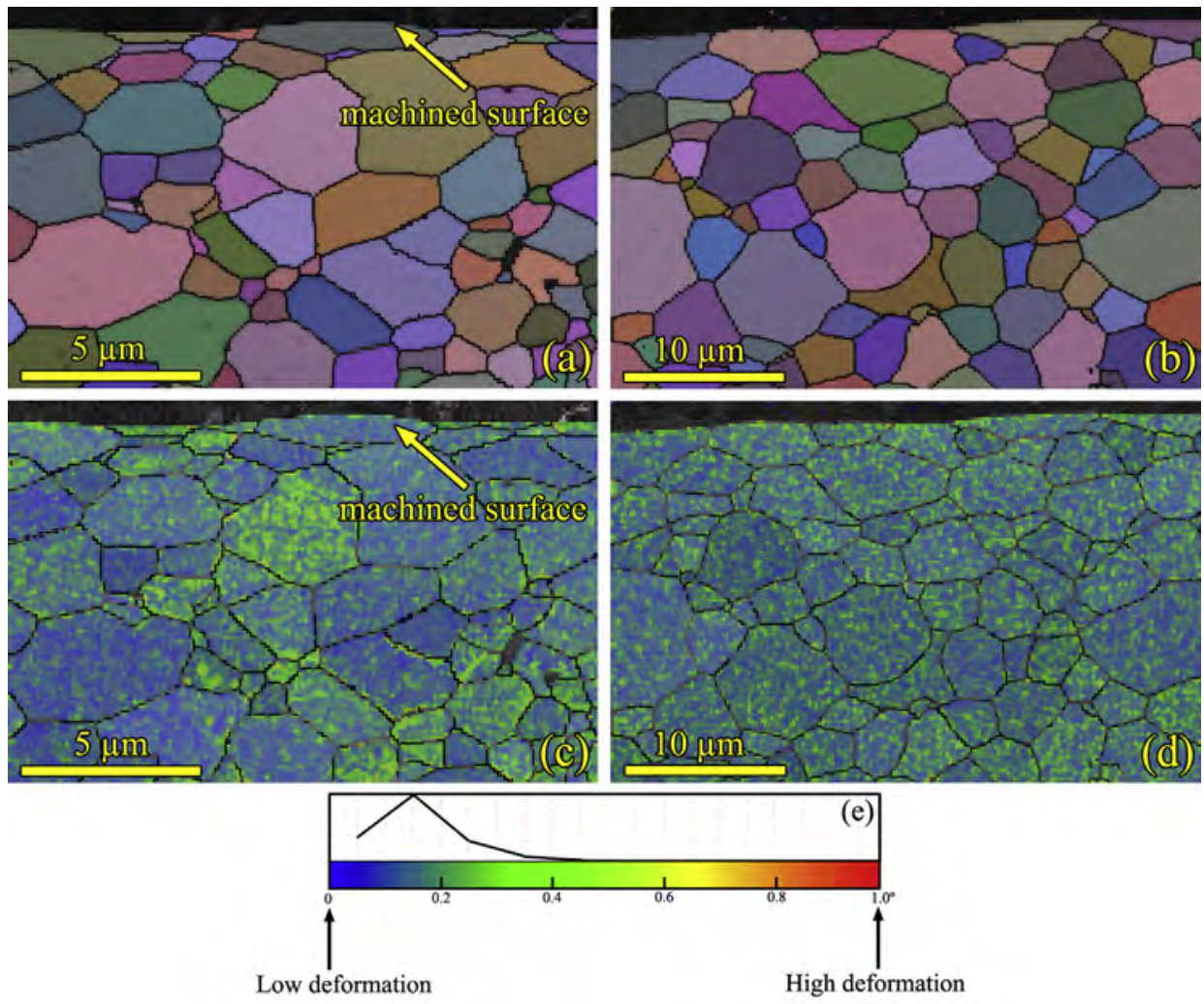

Fig. 2 - EBSD crystallographic orientation map of the cross-section of the superficial area of a laser-machined YSZ membrane (a) and of an unprocessed surface (b). The Local Misorientation maps of the same areas as (a) and (b) are represented in (c) and (d) respectively. (e): Colour scale used in the misorientation maps and histogram of the misorientation distribution in the map (c).

strength of a brittle material is not a characteristic material property. It depends on the size and distribution of flaws, which in turn depend on the fabrication method. In the case of laser-processed materials, surface modification can affect their mechanical properties. Thus, in a very first approximation, we have studied how the surface modification induced by the laser treatment affects the mechanical properties of the samples by three point bending tests. To this end, we use the laser to cut two sets of 36 samples $\left(15 \times 4 \times 0.15 \mathrm{~mm}^{3}\right)$ from two original sintered plates $\left(50 \times 50 \times 0.15 \mathrm{~mm}^{3}\right)$ of the same batch. One of the sets (half of the samples from each sintered plates) was left unaltered for comparison, while the samples of the other set were laser-treated, on only one side, using the same procedure and parameters as for the above-described laser thinning procedure. The only difference was that, in this case, we applied two scans to the central part of the specimen, reducing their thickness by only about $12 \mu \mathrm{m}$. The direction of the first scan was parallel to the long side and the second one parallel to the short side. In the testing jig, the specimens were placed with the laser-treated side face down, in order to get the maximum tensile stress applied to the laser-treated area. In this way, the possible defects caused by the laser treatment determine the breaking load. As we have verified from SEM observations and EBSD experiments that the laser-affected zone is very shallow, this procedure is appropriate to characterize the flaws originated during machining. The maximum bending stress of each specimen was determined by the expression [41]:

$\sigma_{\max }=\frac{3 P L}{2 B t^{2}}$

where $\mathrm{P}$ is the breaking load, $\mathrm{L}$ the support span, $\mathrm{B}$ and $\mathrm{t}$ the specimen width and thickness, respectively. We performed a Weibull analysis of the two collections of samples, lasertreated and untreated, as the strength of a brittle ceramic has intrinsic variability due to the Griffith-like behaviour of defects (i.e. the size, shape and location of the flaws determine the strength of the specimen). We used a two-parameter Weibull distribution and estimated the parameters using the maximum likelihood method [42]. The results are represented in Fig. 3 and Table 2. We obtained a decrease in the bending strength for the laser-treated samples from $224 \pm 14 \mathrm{MPa}$ (Weibull modulus $5.6 \pm 1.4$ ) to $165 \pm 6 \mathrm{MPa}$ (Weibull modulus $9.3 \pm 2.5$ ), i.e. about $26 \%$. No large cracks can be observed in the cross-section of the processed samples, as shown in Fig. 1c. The only mechanical damage that can be observed is the slight debonding between the grains close to the processed surface and the presence of small and shallow cracks (Fig. 4). The closed porosity that can be appreciated in this picture already existed in the samples before the laser treatment. We think that the reduction of the bending strength is probably due to the presence of the afore-mentioned cracks. This does 


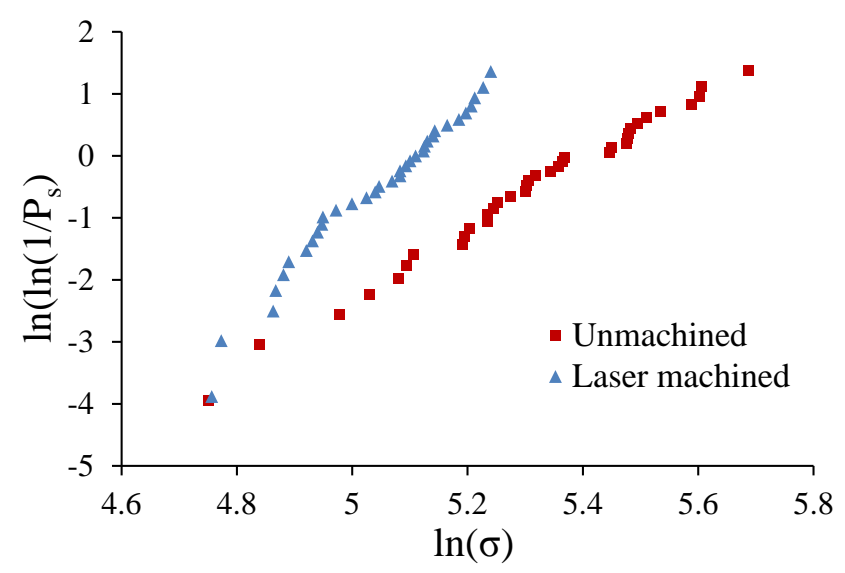

Fig. 3 - Weibull analysis for obtaining the bending strength from three point tests of machined and unmachined samples.

\begin{tabular}{|c|c|c|}
\hline & Strength (MPa) & Weibull modulus \\
\hline Unmachined & $224 \pm 14$ & $5.6 \pm 1.4$ \\
\hline Laser machined & $165 \pm 6$ & $9.3 \pm 2.5$ \\
\hline
\end{tabular}

not represent a very serious deterioration of the mechanical properties and it is compatible with the previous EBSD analysis. In fact, the first cells made on self-supporting thin membranes were able to support the sintering of the electrodes [13]. In any case these cracks are probably produced by the photothermal laser treatment and it is reasonable to presume that they could be avoided using a laser source with shorter pulse width or maintaining the ceramic at high temperature during the laser treatment. Another possibility to

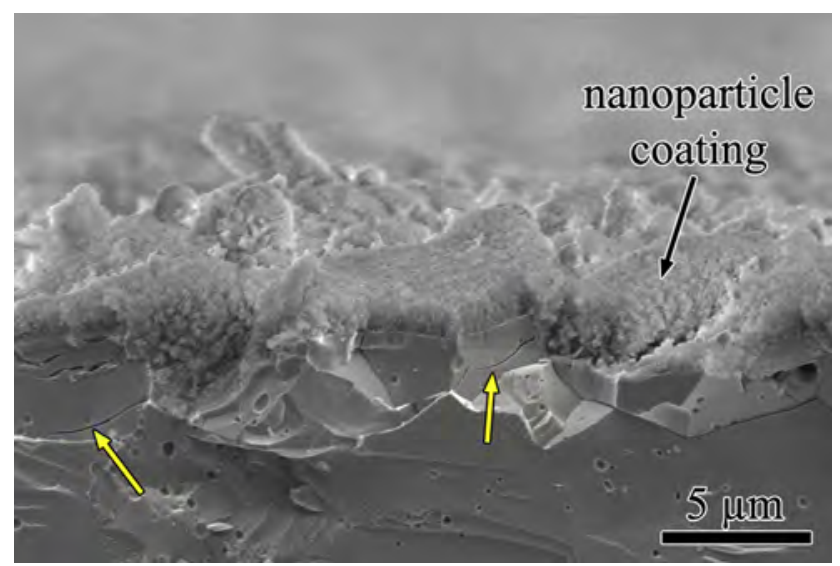

Fig. 4 - SEM cross-section of the laser-treated surface of a YSZ plate. Small debonding of the shallow grains can be observed (some cracks are indicated by yellow arrows). Nanoparticle coating on top of the processed surface is also observed. (For interpretation of the references to colour in this figure legend, the reader is referred to the web version of this article.) prevent these cracks is to machine presintered membranes that would heal the cracks during full sintering.

On the other hand, from the point of view of practical applications, the deterioration of the bending strength can be circumvented by an appropriate design of the device. The maximum load that a ceramic membrane can withstand depends both on its thickness and on the flaw distribution, a part of which is introduced by the laser machining in this case. Thus, we could design the membrane adjusting the size and thickness of the thin areas and of the bounding ribs, previously mentioned in the Laser Machining section, to get membranes with the required mechanical resistance. A calculation by the Finite Element Method (FEM) will be necessary to get final design.

\section{Characterization of the membrane surface}

Although the laser processing parameters, such as pulse separation and overlapping, were selected to minimize the surface roughness of the membrane, according to the optical profilometry it increased to $\mathrm{R}_{\mathrm{a}}=2.5 \mu \mathrm{m}$ as a result of the laser treatment. This roughness, which approximately corresponds to the grain size, can be understood considering the photothermal ablation mechanism. Irradiance values of about $3 \mathrm{GW} \mathrm{cm} \mathrm{cm}^{-2}$ are enough to produce high temperature gradients and local heating along the grain boundaries, where melting and vaporization starts due to energy absorption by scattering mechanisms. This process, combined with the mechanical shockwave generated by the plasma plume, produces intergranular breaking that is followed by ejection of material from the surface [14]. The presence of small cracks at the grain boundaries of the superficial grains is also consistent with this mechanism. It should be noted here that the increased roughness and the microcracking have not been observed in the EBSD experiments due to the special conditions of these experiments. In EBSD experiments we used $20 \mathrm{kV}$ electrons impacting over the $70^{\circ}$ tilted sample. Hence spatial resolution is significantly reduced with respect to usual $3 \mathrm{kV}$ observations and surface roughness is not easily observable.

In addition to the roughness, it is possible to see in Fig. 4 that a thin layer of nanoparticles coats the surface. There are three different possible ways of forming these particles: by direct ejection of solid particles ablated from the surface by a mechanism of intergranular breaking and thermal shock (1), by molten liquid ejection during the ablation process, followed by resolidification of the liquid and deposition onto the surface (2), and by condensation of the vapor formed from the ablation plasma (3). The first mechanism would produce big particles (of the order of the grain size) with sharpened edges, while the other two would produce the nanoparticle coating. This explanation is consistent with the microstructural observations of some dispersed $\sim 1 \mu \mathrm{m}$ size particles on the surface and previous results in highly dense heterogeneous ceramics that also show a bimodal distribution [43].

The nanoparticles deposited on the membrane surface have been characterized by TEM. They were collected placing TEM grids near the processed zones during the laser machining. In addition to the above-mentioned big particles, which were not collected in the TEM grids, two different types of nanoparticles, shown in Fig. 5, were identified: 200-500 nm 


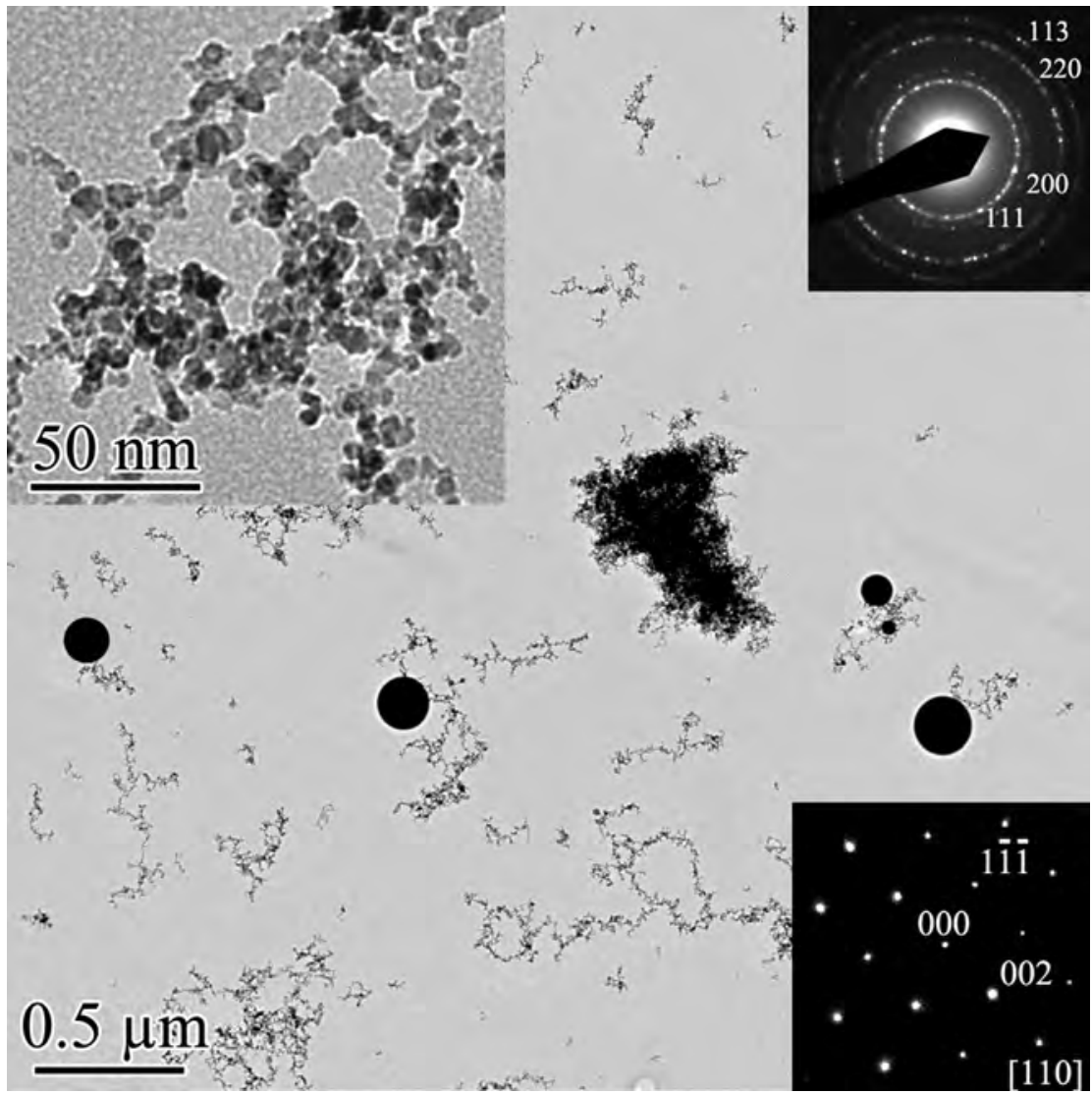

Fig. 5 - TEM images of particles ejected from the ceramic surface during the ablation process showing the two types of resolidified particles. The bottom-right inset is the selected area diffraction pattern (SADP) of a spherical particle along the [110] Ysz zone axis. The top-left inset is a zoom of a cluster of the smaller nanoparticles. The top-right inset shows the diffraction rings, obtained in SADP mode, of a cluster of nanoparticles. The rings are indexed according to the YSZ fluorite structure.

spherical particles and clusters of 3-4 nm particles. We think that the spherical particles come from solidification of ejected molten liquid, while the smaller nanoparticles are formed by nucleation of the evaporated species present within the ablation plasma plume, or by the fragmentation via photophysical mechanisms of bigger particles previously ablated $[44,45]$. Electron diffraction experiments, both in Selected Area and Convergent Beam modes, confirmed that the crystal phase of the nanoparticles was the same as the original cubic YSZ phase (fluorite type, Fm-3m [46]). The yttria content, as determined by EDS, was $7.8 \pm 0.4 \mathrm{Y}_{2} \mathrm{O}_{3}$ mol\% for the spherical particles and $8.4 \pm 1.9 \mathrm{Y}_{2} \mathrm{O}_{3}$ mol\% for the cluster nanoparticles. Thus, the yttria content is compatible with the 8YSZ starting composition, which does correspond to the maximum YSZ ionic conductivity.

The nanoparticle coating could be avoided by using an extracting system to vacuum away the nanoparticles or also by a blowing system. Nevertheless, we believe that in this case the formation of nanoparticle deposits opens new possibilities and, accordingly, we decided to leave unaltered the nanoparticle coating to study its effect on the electrochemical performance of the cell.

\section{EIS measurements of symmetrical cells}

As we have just shown laser machining not only reduces the membrane thickness, but also modifies the electrolyte surface. This could affect the electrolyte-electrode contact. To analyze this issue, we performed Electrochemical Impedance Spectroscopy (EIS) studies of symmetrical cells using LSM-YSZ composite electrodes, for both machined and un-machined samples. We studied only the cathodic polarization because it is higher than anodic polarization in conventional Ni-YSZ/ YSZ/LSM-YSZ cells. For this purpose, as in the previous case for the bending tests, the machined samples were obtained after applying two laser scans, because the objective was to study the polarization resistance of the electrode/electrolyte interface, which is independent of the electrolyte thickness. As shown in Fig. 6, which shows the EIS obtained between 700 and $850{ }^{\circ} \mathrm{C}$, we concluded that there is a small decrease in terms of polarization resistance for the machined sample, compared to a standard and smooth surface sample (between 3 and $7.5 \%$ decrease depending on the temperature), as shown in Table 3. This decrease of the ASR value could be attributed to a better adherence between the electrolyte and the 


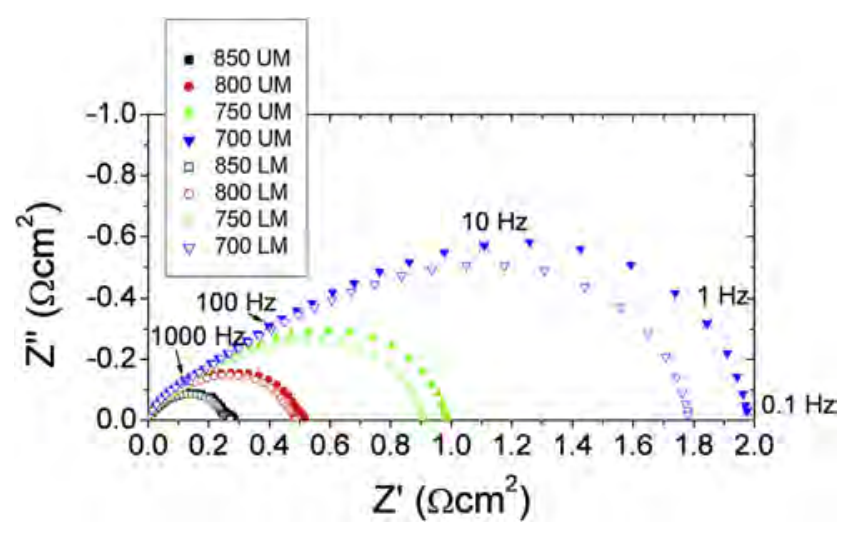

Fig. 6 - EIS spectra of symmetrical cells with LSM-YSZ/LSM composite cathodes showing the results obtained for lasermachined (LM) and unmachined (UM) electrolytes.

Table $\mathbf{3}$ - Polarization resistances of laser-machined and
unmachined membranes $\left(\mathbf{\Omega} \mathbf{~ c m}^{\mathbf{2}}\right)$.
\begin{tabular}{lccc} 
Temperature & $\begin{array}{c}\text { Unmachined } \\
\text { samples }\end{array}$ & $\begin{array}{c}\text { Machined } \\
\text { samples }\end{array}$ & $\begin{array}{c}\text { Polarization } \\
\text { decreasing }(\%)\end{array}$ \\
\hline 650 & 4.03 & 3.85 & 4.60 \\
700 & 1.94 & 1.80 & 7.57 \\
750 & 0.98 & 0.92 & 6.49 \\
800 & 0.53 & 0.50 & 4.61 \\
850 & 0.29 & 0.28 & 3.05 \\
\hline
\end{tabular}

electrode, as a consequence of the presence of redeposited nanoparticles during laser processing and possibly to the increase in surface roughness. For all the studied temperature range $\left(650-850{ }^{\circ} \mathrm{C}\right)$, the main difference in the EIS spectra corresponds to the intermediate frequency component (typical peak frequencies in the range of $10-100 \mathrm{~Hz}$ ). At these frequencies, it is well established in the literature that this process is related to dissociative adsorption, transfer of species at TPB (triple phase boundaries) and surface diffusion [47]. In our case, we have increased the roughness, and thus increased the number of TPBs at the interface. Although this decrease is very modest, we have to bear in mind that the main reduction in resistance is obtained in these systems via the ohmic resistance decrease associated to the thickness reduction. We have just checked that the surface modification induced by laser machining does not deteriorate the electrode-electrolyte contact. In fact it is slightly improved. Moreover, these interesting results are setting up new possibilities, now under consideration, for using laser machining to modify the interface of SOFC electrolytes in order to decrease the electrode/electrolyte polarization. For example, infiltration could be performed at the electrode/electrolyte interphase in order to increase both electronic percolation and electrochemical activation along the grain-surface of the nanostructured coating [48-50].

\section{Conclusion}

Pulsed laser ablation in the nanosecond regime has proved to be a useful tool for preparing thin and self-supporting ceramic electrolytes. We have successfully fabricated 8YSZ membranes with a $20 \mu \mathrm{m}$ thick electrochemical active area and up to $8 \mathrm{~mm}$ in diameter, which is supported by the unprocessed $150 \mu \mathrm{m}$ thick zones. This thickness reduction involves the resulting decrease in ohmic resistance that allows reducing the cell operation temperature. Moreover, merging several thin zones bounded by ribs can enlarge the active area. In fact, in order to avoid buckling as a result of compressive stresses, thinner areas of $20 \mu \mathrm{m}$ thick need to be limited to radius lower than about $0.5 \mathrm{~mm}$.

The self-supporting membranes do not show severe problems of cracking due to laser processing. Moreover, as both thin and thick zones come from the same sintered plate they have full thermo-mechanical integration. EBSD experiments confirmed that the heat-affected layer is less than $2 \mu \mathrm{m}$ in depth. Three point bending tests indicate a deterioration of about $26 \%$ of the bending strength of the membranes, probably due to small debonding of the shallow grains.

SEM and TEM studies confirmed that a thin layer of 8YSZ nanoparticles coats the processed surface, and that this layer is not detrimental to the electrochemical performance of the membranes. On the contrary, EIS experiments showed that the polarization resistance of LSM/YSZ cathodes deposited on the membranes actually decreases by about $5 \%$ in the $650-850{ }^{\circ} \mathrm{C}$ temperature range, in comparison with standard YSZ plates.

\section{Acknowledgments}

This study was funded by the MAT2015-68078-R financed by the Spanish Government (Ministerio de Economía y Competitividad) and the Feder Program of the European Union. The authors would like to acknowledge the use of Servicio General de Apoyo a la Investigación-SAI, Universidad de Zaragoza for the electron microscopy facilities.

\section{R E F E R E N C E S}

[1] Singhal SC, Kendall K. High temperature SOFCs: fundamentals, design and applications. Oxford: Elsevier; 2003.

[2] Orera VM, Laguna-Bercero MA, Larrea A. Fabrication methods and performance in fuel cell and steam electrolysis operation modes of small tubular solid oxide fuel cells: a review. Front Energy Res 2014;2:22.

[3] http://hellokraftwerk.com.

[4] Minh NQ. Ceramic fuel-cells. J Am Ceram Soc 1992;76:563.

[5] Beckel D, Bieberle-Huetter A, Harvey A, Infortuna A, Muecke UP, Prestat M, et al. Thin films for micro solid oxide fuel cells. J Power Sources 2007;173(1):325-45.

[6] Zhu WZ, Deevi SC. A review on the status of anode materials for solid oxide fuel cells. Mat Sci Eng A 2003;362:228.

[7] Sarantaridis D, Atkinson A. Redox cycling of Ni-based solid oxide fuel cell anodes: a review. Fuel Cells 2007;7:246.

[8] Evans A, Bieberle-Huetter A, Rupp JLM, Gauckler LJ. Review on microfabricated micro-solid oxide fuel cell membranes. J Power Sources 2009;194(1):119-29.

[9] An J, Shim JH, Kim YB, Park JS, Lee W, Gur TM, et al. MEMSbased thin-film solid-oxide fuel cells. MRS Bull 2014;39(9):798-804. 
[10] Kerman K, Lai B-K, Ramanathan S. Pt/ $\mathrm{Y}_{0.16} \mathrm{Zr}_{0.84} \mathrm{O}_{1.92} / \mathrm{Pt}$ thin film solid oxide fuel cells: electrode microstructure and stability considerations. J Power Sources 2011;196(5):2608-14.

[11] Tsuchiya M, Lai B-K, Ramanathan S. Scalable nanostructured membranes for solid-oxide fuel cells. Nat Nanotechnol 2011;6(5):282-6.

[12] Baertsch CD, Jensen KF, Hertz JL, Tuller HL, Vengallatore ST, Spearing SM, et al. Fabrication and structural characterization of self-supporting electrolyte membranes for a micro solid-oxide fuel cell. J Mater. Res 2004;19:2604.

[13] Larrea A, Sola D, Laguna-Bercero MA, Peña JI, Merino RI, Orera VM. Self-supporting thin yttria-stabilised zirconia electrolytes for solid oxide fuel cells prepared by laser machining. J Electrochem Soc 2011;158:B1193.

[14] Lahoz R, de la Fuente GF, Pedra JM, Carda JB. Laser engraving of ceramic tiles. Int J App Ceram Tech 2011;8:1208.

[15] Escolastico S, Solis C, Serra JM. Hydrogen separation and stability study of ceramic membranes based on the system $\mathrm{Nd}_{5} \mathrm{LnWO}_{12}$. Int J Hydrogen Energy 2011;36(18):11946-54.

[16] Escolastico S, Solis C, Kjolseth C, Serra JM. Outstanding hydrogen permeation through $\mathrm{CO}_{2}$-stable dual-phase ceramic membranes. Energy Environ Sci 2014;7(11):3736-46.

[17] Cliff G, Lorimer GW. Quantitative analysis of thin specimens. J Microscopy 1975;103:203.

[18] Serrano-Zabaleta S, Laguna-Bercero MA, Ortega-SanMartin L, Larrea A. Orientation relationships and interfaces in directionally solidified eutectics for solid oxide fuel cell anodes. J Eur Ceram Soc 2014;34:2123.

[19] Serrano-Zabaleta S, Larrea A, Stegmann H, Waltenberg C. Electron backscatter diffraction analysis of non-conductive samples using in-situ charge compensation. Microsc Anal 2013;27(6):23 (EU).

[20] Channel 5. Hobro: Oxford Instruments HKL ${ }^{\circledR} ; 2006$.

[21] Monzón H, Laguna-Bercero MA, Larrea A, Arias BI, Varez A, Levenfeld B. Design of industrially scalable microtubular solid oxide fuel cells based on an extruded support. Int J Hydrogen Energy 2014;39:5470.

[22] Green DJ, Guillon O, Rodel J. Constrained sintering: a delicate balance of scales. J Eur Ceram Soc 2008;28(7):1451-66.

[23] Atkinson A, Kim J-S, Rudkin R, Taub S, Wang X. Stress induced by constrained sintering of 3YSZ films measured by substrate creep. J Am Ceram Soc 2011;94(3):717-24.

[24] Ikegami T, Iyi N, Sakaguchi I. Evaluation of sintering stresses of an $\mathrm{Al}_{2} \mathrm{O}_{3}$ powder with a self-loading apparatus. Ceram Int 2009;35(8):3185-94.

[25] Ho S, Hillman C, Lange FF, Suo Z. Surface cracking in layers under biaxial, residual compressive stress. J Am Ceram Soc 1995;78(9):2353-9.

[26] Atkinson A, Selcuk A. Residual stress and fracture of laminated ceramic membranes. Acta Mater 1999;47(3):867-74.

[27] Selcuk A, Atkinson A. Elastic properties of ceramic oxides used in solid oxide fuel cells (SOFC). J Eur Ceram Soc 1997;17(12):1523-32.

[28] Mogensen M, Holtappels P. Ni-based solid oxide electrodes. In: Irvine JTS, Connor P, editors. Solid oxide fuel cells: facts and figures. London: Springer-Verlag; 2013.

[29] Nakajo A, Wuillemin Z, Van Herle J, Favrat D. Simulation of thermal stresses in anode-supported solid oxide fuel cell stacks. Part I: probability of failure of the cells. J Power Sources 2009;193(1):203-15.

[30] Atkinson A, Selcuk A. Mechanical properties of ceramic materials for solid oxide fuel cells. In: Proceedings of the fifth international symposium on solid oxide fuel cellsvol. 97; 1997. p. 671-80.

[31] Selcuk A, Merere G, Atkinson A. The influence of electrodes on the strength of planar zirconia solid oxide fuel cells. J Mater. Sci 2001;36(5):1173-82.

[32] Hearn EJ. Mechanics of materials. 2nd ed. Oxford, UK: Pergamon press; 1985.

[33] Kato T, Wang NS, Negishi A, Momma A, Kasuga Y, Nozaki A. Proceedings of the third international fuel cell conference, Nagoya, Japan, 1999, p. 461.

[34] Kondoh J, Shiota H, Kawachi K, Nakatani T. Yttria concentration dependence of tensile strength in yttriastabilized zirconia. J Alloys Comp 2004;365:253-8.

[35] Timoshenko SP, Green JM. Theory of elastic stability. McGraw-Hill; 1985.

[36] Sola D, Peña JI. Study of the wavelength dependence in laser ablation of advanced ceramics and glass-ceramic materials in the nanosecond range. Materials 2013;6:5302.

[37] Sola D, Escartin A, Cases R, Peña JI. Laser ablation of advanced ceramics and glass-ceramic materials: reference position dependence. Appl Surf Sci 2011;257:5413.

[38] Wright SI, Nowell MM, Field DP. A review of strain analysis using electron backscatter diffraction. Microsc Microanal 2011;17:316.

[39] Bäuerle D. Laser processing and chemistry. 4th ed. Berlin, Heidelberg: Springer-Verlag; 2011.

[40] Hsueh CH, Evans AG. Residual stresses in metal/ceramic bonded strips. J Am Ceram Soc 1985;68(5):241-8.

[41] Courtney TH. Mechanical behavior of materials. Singapore: McGraw-Hill; 1990.

[42] Langlois R. Estimations of Weibull parameters. J Mater. Sci Lett 1991;10:1049.

[43] Lahoz R, Pedra JM, Carda JB, de la Fuente GF. 3rd international congress on ceramics. Osaka, Japan: Ceramic Society of Japan; 2010.

[44] Takiya T, Umezu I, Yaga M, Han M. Nanoparticle formation in the expansion process of a laser ablated plume. J Phys Conf Ser 2007;59:445.

[45] Yang XC, Rieheann W, Dubiel M, Hofmeister H. Nanoscaled ceramic powders produced by laser ablation. Mater. Sci Eng 2002;B95:299.

[46] Lamas DG, Walsoe de Reca NE. X-ray diffraction study of compositionally homogeneous, nanocrystalline yttria-doped zirconia powders. J Mat Sci 2000;35:5563.

[47] Jørgensen MJ, Mogensen M. Impedance of solid oxide fuel cell LSM/YSZ composite cathodes. J Electrochem Soc 2001;148:A433.

[48] Navarrete L, Solís C, Serra JM. Boosting the oxygen reduction reaction mechanisms in IT-SOFC cathodes by catalytic functionalization. J Mater. Chem A 2015;3:16440.

[49] Hanifi AR, Laguna-Bercero MA, Etsell TH, Sarkar P. The effect of electrode infiltration on the performance of tubular solid oxide fuel cells under electrolysis and fuel cell modes. Int J Hydrogen Energy 2015;39:8002.

[50] Samson AJ, Søgaard M, Bonanos N. Electrodes for solid oxide fuel cells based on infiltration of Co-Based materials. Electrochem Solid-State Lett 2012;15:B54. 